\title{
The Paris History and Anthropology Round Table II and the Wenner-Gren Foundation Symposium No. 85
}

\section{Louise A. Tilly}

University of Michigan

The History and Anthropology Round Table II, sponsored by the Max Planck Institut für Geschichte (Göttingen) and the Maison des Sciences de l'Homme (Paris) was held in Paris, June 11-14, 1980. The Round Table brought together 25 historians and anthropologists from West Germany. France, Britain. the United States, Switzerland and Italy. Its topic was Family and Kinship, Material Interest and Emotion.

The "Preliminary Considerations" by Drs. David Sabean and Hans Medick posed the problem: "In analyzing the family, anthropologists and social historians have often found difficulties in handling the relationship between emotional needs and material interest. Rather than carefully sorting out the nature of rights and duties, claims and counter-claims within families in different social and cultural contexts and delineating the corresponding specific territories in which emotion, trust. and sentiment are structured, emotions and interests are treated as opposites which cancel each other out." They noted the danger of simple linear interpretations of temporal change or cross-sectional differences and called for anthropological and historical papers on the following themes: 1) central moments of exchange within the family or household which mediate both emotion and material interest: 2) the interconnection between various planes of activity - the public and the private, the interior and the exterior: 3) specific relationships within the family: 4) the role of kinship in survival strategies. The papers, which were submitted and circulated in advance, addressed these substantive themes in cases ranging from American slave society and New Guinea to seventeenth century France and Italy to twentieth century France, Greece, and England. Discussion was lively and informed. All participants were open to comparative insights and methodologies so there was much stimulating interchange.

Professors Herbert Gutman (CUNY) and Jack Goody (Cambridge University) summed up and pointed to directions for further research. Goody noted that "affective bonds" could only be discussed in a generalized way from anthropological data, and historians can do even less. He remarked that although anthropologists in general tend to see cases as highly individual and particular. the meet- 
ing participants had generally succeeded in locating the situations they were examining in a mode of production and evolutionary process; they had avoided the temptation to compare tendentious concepts like "equality," "love," "individualism" over time or space. He noted that the role in shaping kinship relations of the church in Europe had been neglected and pointed to some important connections. Gutman remarked on methodological and conceptual commonalities in the studies. First was a concern with appropriate categories for analyzing sentiment in subordinate classes, and methods for decoding biased sources. Second were questions and discussion of what observed regularities in behavior (based on analysis of quantitative data) can tell about belief systems. He urged more focus on critical moments of transformation, integration or resistance.

There was general agreement about the importance of the issues raised and caution from practitioners of both disciplines about how far analysis of emotions can go beyond careful attention to structural context and patterned behavior. The historians and anthropologists at this meeting shared respect for context and individual particularities as well as a willingness to combine rich description and theoretical insight.

The Wenner Gren Symposium No. 85, titled The Sex Division of Labor, Development and Women's Status was held at Burg Wartenstein, Austria, August 2-10, 1980. The meeting, organized by anthropologists Helen Safa (formerly Rutgers, now Florida) and Eleanor Leacock (CUNY) brought together anthropologists, sociologists and one historian, myself. There was a nice balance of scholars from England and the United States (6). Australia (1) and third world countries (Africa: 2. Middle East: 1, Asia: 2, Mexico and Latin America: 5). The purpose of the meeting was to treat the general topic by specialized papers which focused on three aspects: 1) the study of the sex division of labor in social evolutionary perspective, 2) the process of "development" and women"s status, and 3) critical moments of change in the transition from peasant to capitalist industrial mode of production. Several participants gave papers which were historical in theme and method: Wanda Minge Klevana on historical changes of the family division of labor, primarily in England, with heavy emphasis on the emergence of modern concepts of childhood: Verena Stolcke on the emergence of free labor in Brazil; Leith Mullings on uneven development, class, ethnicity and gender in the United States to about 1900; Kate Young on the interrelations beiween and among demographic change, economic change and gender relations in Europe; Louise Tilly on the sex division of labor in women's collective action in nineteenth century France: and Simi Atonja on the "African Mode of Production," women and work in West Africa.

The European historical experience seemed to have most in common with what is going on now in Mexico and Latin America (addressed in papers by Lourdes Arizpe, Lourdes Beneria, Maria Patricia Fernandez, Magdalena Leon de Leal, Helen Sata, and Verena Stolcke). These scholars agreed that "development" was a misleading word and hollow concept. Their studies showed that 
proletarianization transferred men and women from peasant household production into wage labor in sectors frequently controlled by European or North American capital. As in Europe, in the short run, proletarianization is not raising people's standard of living or producing a more egalitarian society. Men and women are unequally affected, and women's wage work is concentrated in the most precarious and unstable sectors. The current promotion of export industries in Mexico, for example, is simply the other side of the phenomenon of runaway shops. Men's migration to work in cities or in developed countries is leading to high incidence of female-headed households. Agro industry is no panacea for the Mexican economy and women's work in industries like strawberry packing is vulnerable to the companies' whims. If the workers organize to resist, the companies move elsewhere. For the Latin American scholars, the persistence of weak and unevenly developed economies is a troubling and difficult-to-solve problem. They also showed that wage labor is contributing to continued sex inequality and, in some cases, as that of highly exploited Brazilian wage laborers in coffee plantations, to increased instability in relations between the sexes and violence against women.

These developments are not dissimilar to some in nineteenth century Europe. By the nineteenth century, European proletarianization was more often urban than rural and it took place in a national context of rural to urban migration more often than in international migration. The exception of course was the enormous migration to the United States. The personal costs of exploitation of immigrants, and overcrowding and poverty in urban centers, the wrenching effects on family life under conditions of low wages and long hours are doubly dramatic when they can be directly observed, touched, smelled.

The concluding summary by Maria Patricia Fernandez noted the contributions of the papers in three important areas. In the area of theory, there was agreement on a broader definition of "development" which would include more than simple economic change but also changes in political and social/cultural relationships on the household and individual level. The use of concepts such as choices and access to resources dramatizes and pinpoints the areas of non-development in "development." However, there was no agreement on whether the household sex division of labor is a cause or a reflection of the interface of socictal division of labor and mode of production. Some contributors argued that the strict division of men's and women's roles into domains does not necessarily imply subordination: it is the context which defines the situation as subordination or not. Others insisted that the transition from subsistence agriculture to wage labor leads to a loss of political autonomy of groups and individuation of workers and their family which gives individual men more control over reproduction and a chance to exploit women. There were different interpretations of the connections between patriarchy (defined broadly as asymmetry of sex roles and differentiated access to resources) and capitalism. Several papers made the point that domestic labor is a mechanism which subsidizes capital accumulation while retaining women as an important reserve of wage labor. Most agreed that women are subordinated not because their 
work is unimportant but because it is primarily in the area of reproduction, the importance of which is frequently devalued. There is no easy solution to this dilemma.

These abstractions should not obscure the fact that all the papers were grounded in time and place and provided empirical and descriptive evidence for their generalizations. Thus there were studies which made methodological contributions in the study of labor market stratification, labor market mediation between household and process of capital accumulation, the articulation of household/reproduction/and market production, wage differentials, the relationship between cultural perceptions of women's subordination and their labor force participation, and, finally, women's political participation and ways in which women are sometimes controlled for political ends. There was also a concluding discussion about policy implications of the various studies.

The meeting was a fruitful and exciting international exchange which brought together social scientists interested in comparisons over time and space who insisted on specification of the questions to be addressed and systematic attention to categories of gender, class and ethnic group. 